\title{
Investigation of reliability assessement in power electronics circuits using machine learning
}

\author{
Soumya Rani Mestha, Pinto Pius A.J. \\ Department of Electrical and Electronics Engineering, NMAM Institute of Technology, Karnataka, India
}

\begin{tabular}{l} 
Article Info \\
\hline Article history: \\
Received Aug 28, 2020 \\
Revised Jan 12, 2021 \\
Accepted Feb 2, 2021 \\
\hline
\end{tabular}

\section{Keywords:}

Condition monitoring

Life cycle

Machine learning

Power electronics

Prognosis

Remaining useful life

\begin{abstract}
Recent advances in power electronics (PE) and machine learning (ML) have prompted the technologists to adapt these new technologies to improve the reliability of PE systems. During the process, a lot of investigations on the performance and reliability of PE systems is carried out. The intention of this paper is to present a comprehensive study of advances in the field of reliability of PE systems using machine learning. Recent publications in this regard are analysed and findings are tabulated. In addition to this, literatures published in the prediction of remaining useful life (RUL) of power electronic components is discussed with emphasis on its limitations.
\end{abstract}

This is an open access article under the $\underline{C C B Y-S A}$ license.

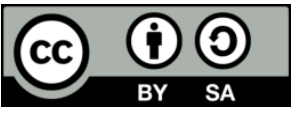

\section{Corresponding Author:}

Soumya Rani Mestha

Departement of Electrical and Electronics Engineering

NMAM Institute of Technology

Nitte 574110, Udupi District, Karnataka, India

Email: vs.soumya@nitte.edu.in

\section{INTRODUCTION}

Invention of thyristor in the year 1957 has created a new era in the field of power electronics. Since then, power electronics has found its way in the wide range of applications right from power generation to end-user consumption of electricity. Thorough research and improvements in the semiconductor technologies, converter circuit technology especially in controlled rectifiers [1], [2] has improved performance of the power electronics systems with respect to efficiency and switching speeds. Power electronics components are mainly used in power conversion systems due to their switching capability and efficiency. However, these components tend to get exposed to current surges, high temperatures and continuous switching operations leading to the possibility of power electronics components failing to operate in the expected manner.

Owing to the safety requirements, the automotive (EV) and aerospace industries have brought in the stringent norms in the field of reliability of power electronics systems. Yantao et al [3] mentions that power semiconductor as well as electrolytic capacitors are most susceptible to failures. Failure of any of these, may be one or more components could be a catastrophe provided appropriate fault handling mechanisms are not in place. As per the study conducted [4] on PV modules, power inverters accounted for $37 \%$ of unscheduled maintenance incidents by component and contributed for $59 \%$ of unscheduled maintenance expenditures. 


\section{NOTION OF RELIABILITY IN POWER ELECTRONICS}

In power electronics circuits (PEC), faults can be either intrinsic (chip related-mostly occur due to high current or voltage) or extrinsic (package related-mostly occur due to thermo-mechanical stress). Reliability in PEC was introduced as early as 1950s [5]. As mentioned in [6], reliability is the probability of any part or the entire system that continues to work without any interruption over a period of time. Reliability may be defined as (1)

$$
R(t)=e^{-t / M T B F}
$$

where MTBF = Mean time between failures.

The reliability function $R(t)$ versus time $[0, t]$ is plotted in Figure 1 the shape of which resembles bathtub which is the life-cycle of a component. The graph has three distinct phases, namely, burn-in, useful life and the wear-out periods [7, 8]. Every component which comes out of asssembly line is rolled out after the execution of extensive testing processes to handle the infant-mortality rate. However, defects do creep in during the design as well as production phases leading to increase in the failure rate during the first phase.

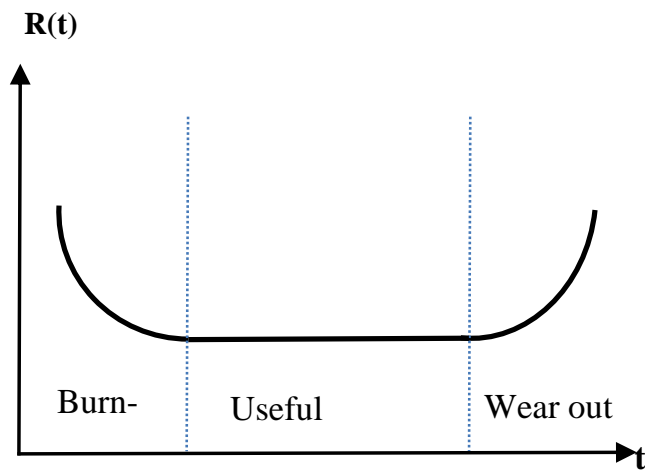

Figure 1. Failure rate curve as a function of time

Once the component successfully completes the first phase, the rate of failure remains flat for a portion of time which indicates the stabilization in the health of the component. Post useful life phase, failure rate increases exponentially. However, by this time the component might have completed its intended purpose.

A lot of research has been already carried out by researchers to make the power electronics systems reliable, ensure high availability with long lifetime and requiring very less maintenance cost. Various faulttolerant design and control strategies, pattern recognition algorithms have been proposed for making PE systems reliable [9]-[13]. Industries are focussing on Design for Reliability [14] rather than depending on usual way of testing for reliability. Along with these, recent advances in Machine Learnings (ML) have shown great potential in making power electronics systems more reliable [15]-[18]. Condition monitoring (CM) [19] is a process of observing operating characteristics of an electrical system to detect any anomaly in its characteristics. For CM, it is imperative to have decision making algorithms, that decide based on these current measurements and historical data.

In Figure 2, the difference between diagnosis and prognosis is depicted. Assessing the present health of a component and predicting the future health is termed as Prognosis [20] whereas Diagnosis is the process of identifying the nature of failure by external examination. For a successful CM system, accurate prognosis plays important role.

The assessment can be carried out using sensor data obtained by monitoring

a. component's usage rate and period, ambient temperature and humidity, vibration and shock collectively termed as component's life cycle environment

b. divergence of operating parameters from their usual values characterized as performance degradation

c. material disintegrating, oxidization, increase in electrical resistance or threshold voltage.

The data so obtained can then be analysed using prognostic algorithms, predominantly, machine learning based on which conclusions can be drawn, the details of which will be discussed in the subsequent sections of this paper. Outcome of the algorithm can then be used for maintenance forecasting, fault detection and advanced warning of failures. 


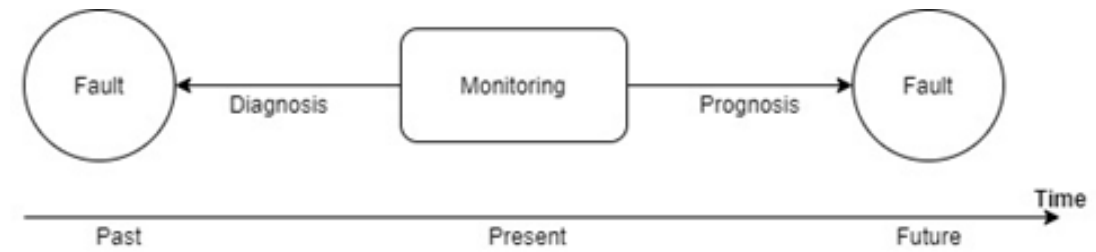

Figure 2. Difference between diagnosis and prognosis

Figure 3 gives a glimpse of number of publications in the field of Power Systems reliability using ML approach for the last ten years. It can be observed that ML approach in reliability has garnered much more interest since 2017. It is a clear indication that scientific and research community has found the prospect and potential in ML's ability in the field of power systems reliability. There have been several surveys published for reliability of electrical systems [21]-[27]. However, this paper gives a broad overview of prognostic or proactive methods limiting the scope to the use of ML for reliability in power electronics systems.

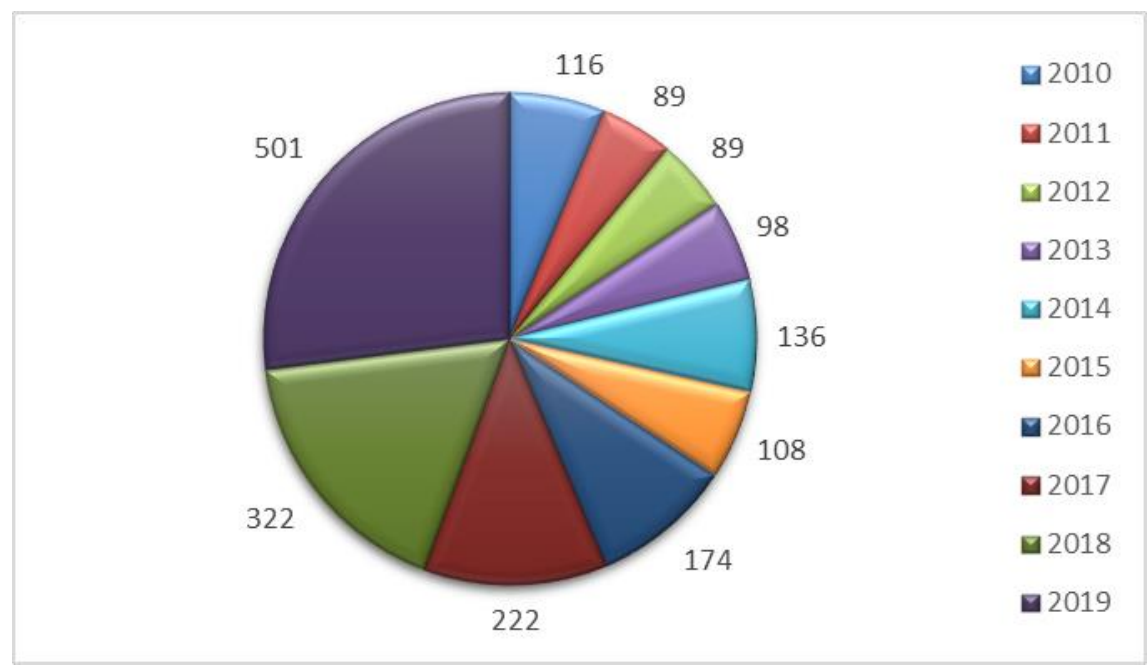

Figure 3. Chart represents number of publications in the field of power systems reliability using ML approach. Source: ieeexplore.ieee.org

\section{PROGNOSIS BY MACHINE LEARNING}

PE system's maintenance plays key role in the safety of personnel and equipment. If the system should provide business continuity of service with high efficiency, the total cost of ownership naturally increases. Maintenance activities can be broadly classified into three types Reactive, Preventive and Predictive which are summarized in Table 1 [28], [29]. From the table, it can be inferred that, predictive maintenance has clear advantage over other types of maintenance approaches. Feldman et al. [30] study on a display system of Boeing 737 plane revealed that, a ROI of 3.5:1 acheieved when the predictive maintenance was employed instead of reactive maintenance. Also, in power conveters short circuit and degradation faults do not trigger any fault protection mechanism which is an ideal scenario for predictive maintenance.

Total Productive Maintenance (TPM) [31] endorsed as Japanese approach to effective maintenance management developed by Deming to enhance overall equipment effectiveness (OEE) which tend to use predictive maintenance approaches. The OEE can be defined as

$\mathrm{OEE}=$ Availability $\times$ Performance Rate $\times$ Quality Rate

where

$$
A=\frac{(R A-D)}{R A} \times 100
$$


where A: Availability, RA: Required Availability, D: Downtime

$$
\mathrm{PR}=\frac{\mathrm{DCT} \times \text { Output }}{\mathrm{OT}} \times 100
$$

where PR: Performance Rate, DCT: Design Cycle Time, OT: Operating Time

$$
\mathrm{QR}=\frac{\mathrm{PI}-\mathrm{QD}}{\mathrm{PI}} \times 100
$$

where QR: Quality Rate, PI: Production Input, QD: Quality Defect, PI: Production Input

\begin{tabular}{|c|c|c|}
\hline Maintenance Types & Description & Applications \\
\hline $\begin{array}{l}\text { Reactive Maintenance } \\
\text { (RM) }\end{array}$ & $\begin{array}{l}\text { Corrective based, usually referred to as repair that restores the } \\
\text { required function of a faulty item; Advantages, Low cost, } \\
\text { Disadvantages: } \\
\text { a. Cost associated with replacing the failed part could be more } \\
\text { owing to the maintenance of spare parts inventory } \\
\text { b. Possible secondary equipment damage due to the cascading } \\
\text { effect }\end{array}$ & $\begin{array}{l}\text { a. Small parts and equipment } \\
\text { b. Non-critical equipment } \\
\text { c. Equipment unlikely to fail } \\
\text { d. Redundant systems }\end{array}$ \\
\hline $\begin{array}{l}\text { Preventive } \\
\text { Maintenance (PM) }\end{array}$ & $\begin{array}{l}\text { Diagnostics based, avoids any possible failure by regular } \\
\text { inspection conducted during a scheduled shutdown/still working } \\
\text { to minimize its impact on business operations } \\
\text { Advantages: } \\
\text { a. Bathtub curve can be used to predict failure rate of the } \\
\text { equipment b. Flexibility allows for the adjustment of maintenance } \\
\text { periodicity }\end{array}$ & $\begin{array}{l}\text { a. Most frequently used } \\
\text { equipments } \\
\text { b. Consumables } \\
\text { c. Kind of equipments having } \\
\text { a history of failures } \\
\text { d. Manufacturer } \\
\text { recommendations }\end{array}$ \\
\hline & $\begin{array}{l}\text { Disadvantages: } \\
\text { a. Since wear-out period is based on theory rather than actual } \\
\text { data, PM becomes an expensive strategy } \\
\text { b. Labor intensive }\end{array}$ & \\
\hline $\begin{array}{l}\text { Predictive Maintenance } \\
(\mathrm{PdM})\end{array}$ & $\begin{array}{l}\text { It is about equipment condition monitoring using advanced sensor } \\
\text { and instrumentation technologies, and its repetitive analysis using } \\
\text { predictive algorithms } \\
\text { Advantages: } \\
\text { a. Though PM requires high investment, it is worth the money } \\
\text { since it provides extended life to the equipment. } \\
\text { b. Provides a preemptive approach for safeguarding the } \\
\text { equipment. } \\
\text { c. Reduces the downtime of the equipment. }\end{array}$ & $\begin{array}{l}\text { a. Equipment with random } \\
\text { failure patterns } \\
\text { b. Critical equipment } \\
\text { c. Kind of equipments that } \\
\text { are less likely to wear and } \\
\text { tear }\end{array}$ \\
\hline & $\begin{array}{l}\text { Disadvantages: } \\
\text { a. Increased investment in diagnostic equipment }\end{array}$ & \\
\hline
\end{tabular}

Table 1. Reactive, preventive and predictive maintenance types

In particular, PM has given rise to a collection of methodologies, namely, probabilistic approach and a fully data driven approach that relies upon ML [32]. In a nutshell, ML comprises of a variety of statistical, probabilistic and optimization techniques that learns from the set of data and becomes intelligent enough to make judgements without human intervention. ML algorithms with emphasis on non-linear models like support vector machines (SVM), decision trees, logistic regression and artificial neural networks as predictive modelling tools have greater predictive performance and are quite popular among researchers [33], [34]. Table 2 aptly summarizes the recent publications on ML algorithms used in prognosis of PE circuits. It is observed that a combination of ML algorithms is used to boost the efficiency of the approach. For example, SVM is computationally heavy, hence requires more training time. By introducing least square to the cost function, the computational complexity is reduced. 
Table 2. Literature review on ML approach for reliability in PE system's

\begin{tabular}{|c|c|c|c|c|}
\hline Sl. No & References & $\begin{array}{l}\text { Machine Learning } \\
\text { Techniques }\end{array}$ & Component/System & $\begin{array}{l}\text { Pros and Cons (As claimed by the } \\
\text { respective authors) }\end{array}$ \\
\hline 1 & $\begin{array}{l}\text { Aravid Sai Sarathi } \\
\text { Vasan, et al [35]- } \\
{[37]}\end{array}$ & $\begin{array}{l}\text { Least Square SVM(LS- } \\
\text { SVM) }\end{array}$ & $\begin{array}{l}\text { Bandpass and Low } \\
\text { Pass filters }\end{array}$ & $\begin{array}{ll}\text { - } & \text { Used to evaluate RUP } \\
\text { - } & \text { Early fault detection and } \\
\text { isolation } \\
\text { - } \\
\text { Decreases complexity }\end{array}$ \\
\hline 2 & $\begin{array}{l}\text { Xi -Shan Zhang } \\
\text { et.al,[38] }\end{array}$ & Support Vector Machines & $\begin{array}{l}\text { Complex electronic } \\
\text { system } \\
\text { Biquad filter }\end{array}$ & $\begin{array}{l}\text { - Long term operation of the } \\
\text { system } \\
\text { - } \\
\text { Reliability analysis using } \\
\text { Kaplan-Meier (KM) and Kernel } \\
\text { density Estimation (KDE) }\end{array}$ \\
\hline 3 & $\begin{array}{l}\text { LanHai and } \\
\text { LiuHong- da, et. al, } \\
\text { [39] }\end{array}$ & $\begin{array}{l}\text { SVM and Principal } \\
\text { Component Analysis (PCA) }\end{array}$ & $\begin{array}{l}\text { Three -Phase rectifier } \\
\text { circuits }\end{array}$ & $\begin{array}{l}\text { - Improves generalization ability } \\
\text { - Capable of locating faults } \\
\text { precisely }\end{array}$ \\
\hline 4 & $\begin{array}{l}\text { Jianchen Wang, et } \\
\text { al [40] }\end{array}$ & $\begin{array}{l}\text { Chaos theory and Particle } \\
\text { Swarm Optimization } \\
\text { (CPSO)-SVM }\end{array}$ & Elliptical filter circuit & $\begin{array}{l}\text { - Improves efficiency } \\
\text { - Execution time is less }\end{array}$ \\
\hline 5 & $\begin{array}{l}\text { Shaowei Chen, et } \\
\text { al, [41] }\end{array}$ & $\begin{array}{l}\text { Genetic Algorithm (GA) - } \\
\text { SVM }\end{array}$ & $\begin{array}{l}\text { Quad high pass filter } \\
\text { circuit }\end{array}$ & $\begin{array}{l}\text { - Prevents dependence of large } \\
\text { training samples } \\
\text { - Better success rate of } \\
\text { diagnosibilty }\end{array}$ \\
\hline 6 & $\begin{array}{l}\text { Qingfeng Ma, et al } \\
\text { [42] }\end{array}$ & $\begin{array}{l}\text { Decision Tree (DT) and } \\
\text { BSVM }\end{array}$ & $\begin{array}{l}\text { Sallen-key bandpass } \\
\text { filter } \\
\text { Active band-stop } \\
\text { filter circuit }\end{array}$ & $\begin{array}{l}\text { - Execution time is less } \\
\text { - Testing accuracy is high }\end{array}$ \\
\hline 8 & $\begin{array}{l}\text { Tang Jingyuan, et } \\
\text { al [43] }\end{array}$ & SVM and Adaboost & $\begin{array}{l}\text { Two-stage four op- } \\
\text { amp biquad low-pass } \\
\text { filter }\end{array}$ & - Classification accuracy is high \\
\hline 10 & $\begin{array}{l}\text { WEI HE, et al, [44] } \\
\text { Mehrdad } \\
\text { Biglarbegian, et al } \\
{[45]}\end{array}$ & Naïve Bayes Classifier & $\begin{array}{l}\text { Opamp biquad filter } \\
\text { circuit. } \\
\text { Gallium Nitride } \\
(\mathrm{GaN}) \text { transistors. }\end{array}$ & $\begin{array}{ll}\text { - } & \text { Effective fault diagnosing } \\
\text { - } & \text { High latency } \\
\text { - } & \text { Enhances system reliability }\end{array}$ \\
\hline 11 & Piotr Bilski [46] & Random Forest (RF) & $\begin{array}{l}\text { 5th order lowpass } \\
\text { filter. }\end{array}$ & $\begin{array}{l}\text { - Used to detect parametric faults } \\
\text { - High accuracy }\end{array}$ \\
\hline 13 & $\begin{array}{l}\text { Seongmin Heo, } \\
{[47]} \\
\text { Mehrdad } \\
\text { Biglarbegian [48] }\end{array}$ & $\begin{array}{l}\text { ANN } \\
\text { Recurrent Neural Network } \\
\text { (RNN) }\end{array}$ & $\begin{array}{l}\text { Neural network } \\
\text { classifiers - } \\
\text { Tennessee Eastman } \\
\text { (TE) } \\
\text { Gallium Nitride } \\
\text { (GaN) power } \\
\text { converters }\end{array}$ & $\begin{array}{l}\text { Increased fault detection } \\
\text { accuracy } \\
\text { Better fault detection and } \\
\text { classification }\end{array}$ \\
\hline 15 & Q. Sun, et al, [49] & $\begin{array}{l}\text { Crow Search Algorithm - } \\
\text { LSSVM }\end{array}$ & $\begin{array}{l}\text { Capacitor -open loop } \\
\text { Boost converter }\end{array}$ & $\begin{array}{l}\text { - High computational efficiency } \\
\text { - } \quad \text { Good estimation accuracy }\end{array}$ \\
\hline 16 & W. Chen, et al [50] & $\begin{array}{l}\text { PCA (Unsupervised } \\
\text { algorithm) }\end{array}$ & SiC -MOSFET & $\begin{array}{l}\text { Used for offline as well as } \\
\text { online fault detection }\end{array}$ \\
\hline 17 & B. Gou,et al [51] & $\begin{array}{l}\text { IGBT 3-phase PWM } \\
\text { inverter }\end{array}$ & $\begin{array}{l}\text { Random Vector } \\
\text { Functional L ink } \\
\text { (RVFL) network }\end{array}$ & $\begin{array}{l}\text { - Fault prediction accuracy of } \\
98.83 \% \\
\text { - } \quad \text { Applied to non -linear systems }\end{array}$ \\
\hline
\end{tabular}

\section{REMAINING USEFUL LIFE (RUL)}

For an efficient prognosis, estimation of RUL plays a critical role. RUL can be defined as number of productive hours left in a component at a point of time while it is operating. It can be also termed as useful time left till next maintenance. Based on how the available information is used, the prognostic methodologies are classified into model or physics-driven, data or machine learning-driven and hybrid approaches [52]-[54]. In data driven methodology, degradation characteristics are computed based on the chronological sensor data to train the system model that may be used to compute RUL of the component. Widely applied algorithms include Gaussian process [55], [56], SVM, Least Square SVM (LSSVM) [57], neural networks [58], [59], gamma processes [60] and Hidden Markov Models (HMMs) [61]. Physics based approach demands substantial prior understanding about physical systems which is rare to find in practice. The mathematical models are built on first principle or comprehension of component's failure mechanism. Eyring model [62], Weibull distribution [63], particle filter [64], Bayesian inference-based methods [65] are some of the commonly used algorithms in physical modeling approach. Hybrid models are the combination of both the Data driven approach and Physical modeling based approach. In case of non-linear systems, hybrid models can scale from component level to system level [66]. Based on the failure modes, a component can have various deterioration curves which might result in varied RUL [67]. 
The following section discusses the work carried out on PdM for reliability assessment of PE systems. Vasan, et al [35] used LSSVM algorithm to address the concerns of the circuit failure by predicting and isolating faults. They also estimated the RUP ((Remaining Useful Performance) by using Bayesian Monte Carlo approach for the filter circuits. Thus, aiding the prevention of system failures [36], [37]. XiShan Zhang, et al [38] proposed fault prognostic technique to realize health management of the complex electronic equipment using SVM algorithm. Reliability analysis is done using Kaplan-Meier (KM) and Kernel density Estimation (KDE) technique. Combining SVM algorithm and Principal Component Analysis (PCA) it is possible to locate the position of the power system faults. It will also help in identifying the type of the fault and reduce the interruption of the system [39]. Jianchen Wang, et al [40] proposed Chaos theory and Particle Swarm Optimization (CPSO)-SVM to enhance the system performance by reducing the execution time. Reliability analysis can also be done using genetic algorithm (GA). GA can also be used to increase the success rate in fault diagnosis [41]. Using decision tree algorithm, execution time can be minimized, thereby improvinig the efficiency of the system [42]. Combining SVM and Adaboost algorithm yields better reliability and high classification accuracy [43]. A probabilistic classifier, Naïve Bayes (NB) algorithm provides accurate results and consumes less training time [44], [45]. The approach is used to detect parametric faults in the fifth order lowpass filter, RF is the favorable classification approach with high efficiency even on the quite small data sets [46]. Neural network classifier and Gallium Nitride (GaN) converters are used in reliability analysis for better fault classification and detection. GaN-based devices have incredible performance and exhibit better material properties when compared to those devices made up of silicon. Using GaN device would be highly useful for power engineers in enhancing the reliability of the system [47], [48]. Crow Search Algorithm-LSSVM is novel approach which yields high computational efficiency for boost converters [49]. An unsupervised algorithm is used for fault prognosis where online as well as offline faults can be detected [50]. Fast Fourier Transforms (FFT) is used by IGBT 3-phase PWM inverter to extract the fault frequency spectrum of three-phase currents.

\section{RESULTS AND DISCUSSION}

More than 150 papers were reviewed and 67 of them are mentioned in the reference to explain the significance of machine learning in the reliability domain. ML's use in PEC reliability comes with both challenges and opportunities. Prognosis requires live condition monitoring which may be a challenge in itself due to accessibility and environment conditions. ML algorithms are not scable in a way that a particular algorithm is trained and tested for lower rated device may not be suitable for higher rated device. Majority of the reviewed papers have published their results based on the laboratory conditions or using simulation software. However real-world scenarios may vary.

\section{CONCLUSION}

With the complexities involved in PE Systems, their safety, maintenance and reliability are the major concerns. This paper focuses on providing a review of reliability assessment for PE systems using ML techniques. The advantages, disadvantages and applications of various types of maintenance schemes are discussed in detail. A paradigm shifts towards use of ML has been observed in the approach of handling reliability concerns in PEC. Several ML algorithms have proven their efficacy in the area of reliability and in the better fault prediction models. Prediction of faults take cautionary measures to avoid significant and insubstantial losses in the system. Combining ML algorithm yields better results in achieving highly reliable PE systems. Finding RUL itself is a challenging task. However, it provides an insight into the health of the system. This literature review has been developed to investigate various methods in assessing the reliability of PE systems using ML approach for the benefit of power engineers and researchers.

\section{REFERENCES}

[1] J. D. van Wyk and F. C. Lee, "On a future for power electronics," IEEE J. Emerg. Sel. Top. Power Electron, vol. 1, no. 2, pp. 59-72, 2013.

[2] J. C. Balda and A. Mantooth, "Power-semiconductor devices and components for new power converter developments: a key enabler for ultrahigh efficiency power electronics," IEEE Power Electron. Mag, vol. 3, no. 2, pp. 53-56, 2016.

[3] Y. Song and B. Wang, "Survey on Reliability of Power Electronic Systems," IEEE Transactions On Power Electronics, vol. 28, no. 1, Jan. 2013.

[4] H. Wang et al., "Transitioning to Physics-of-Failure as a Reliability Driver in Power Electronics," in IEEE Journal of Emerging and Selected Topics in Power Electronics, vol. 2, no. 1, pp. 97-114, Mar. 2014.

[5] L. M. Moore and H. N. Post, "Five years of operating experience at a large, utility-scale photovoltaic generating plant," Prog. Photovolt.: Res. Appl, vol. 16, no. 3, pp. 249-259, 2008. 
[6] IEEE Standard Dictionary of Electrical and Electronics Terms, IEEE, Std 100-1996.

[7] R. K. Mobley, "An introduction to predictive maintenance,” Elsevier. 2002.

[8] M. S. Alvarez-Alvarado et al., "Bathtub curve as a markovian process to describe the reliability of repairable components," IET Generation, Transmission Distribution, vol. 12, no. 21, pp. 5683-5689, 2018.

[9] R. Peuget et al., "Fault detection and isolation on a PWM inverter by knowledge-based model," IEEE Trans. Ind. Appl, vol. 34, no. 6, pp. 1318-1326, 1998.

[10] D. Diallo et al., "Fault detection and diagnosis in an induction machine drive: A pattern recognition approach based on concordia stator mean current vector," IEEE Trans. Energy Conv, vol. 20, no. 3, pp. 512-519, Sep. 2005.

[11] S. Khomfoi et al., "Fault diagnosis and reconfiguration for multilevel inverter drive using AI-based techniques," IEEE Trans. Ind. Electron, vol. 54, no. 6, pp. 2954-2968, Dec. 2007.

[12] Q. T. An et al., "Switching function modelbased fast-diagnostic method of open-switch faults in inverters without sensors," IEEE Trans. Power Electron, vol. 26, no. 1, pp. 119-126, Jan. 2010.

[13] O. Wallmark et al., "Control algorithms for a fault-tolerant PMSM drive," IEEE Trans. Ind. Electron, vol. 54, no. 4, pp. 1973-1980, Aug. 2007.

[14] P. O'Connor et al., "Practical reliability engineering," the 5 edition, John Wiley \& Sons, 2012.

[15] Y. Chen et al., "Modeling and optimization of complex building energy systems with deep neural networks," in Signals, Systems, and Computers, 2017 51st Asilomar Conference on. IEEE, 2017, pp. 1368-1373.

[16] X. Y. Chen et al., "An unsupervised deep learning approach for scenario forecasts," Power Systems Computation Conference (PSCC), 2018.

[17] T. Hong et al., "Probabilistic energy forecasting: Global energy forecasting competition 2014 and beyond," International Journal of Forecasting, vol. 32, no. 3, pp. 896-913, 2016.

[18] Y. Wang et al., "Deep learning-based socio-demographic information identification from smart meter data," IEEE Transactions on Smart Grid, 2018.

[19] Y. Han et al., "Condition monitoring techniques for electrical equipment-a literature survey," IEEE Trans. Power Del, vol. 18, no. 1, pp. 4-13, Jan. 2003.

[20] T. Brotherton et al., "Prognosis of faults in gas turbine engines," in Proc. IEEE Aerosp. Conf., 2000, pp. 163-171.

[21] Y. Ran et al., "A Survey of Predictive Maintenance: Systems, Purposes and Approaches," arXiv: 1912.07383, 2019.

[22] S. Yang et al., "An industry-based survey of relibility in power electronic converters," The ECCE Conf. Rec., San Jose, CA, Sep. 2009.

[23] S. Khan et al., "A review on the application of deep learning in system health management," Mechanical Systems and Signal Processing, vol. 107, pp. 241-265, 2018.

[24] S. Zhang et al., "Machine learning and deep learning algorithms for bearing fault diagnostics-a comprehensive review," arXiv preprint arXiv: 1901.08247, 2019.

[25] S. Katipamula et al., "Methods for fault detection, diagnostics, and prognostics for building systems: a review, part i," Hvac\&R Research, vol. 11, no. 1, pp. 3-25, 2005.

[26] Y. Lei et al., "Machinery health prognostics: A systematic review from data acquisition to rul prediction," Mechanical Systems and Signal Processing, vol. 104, pp. 799-834, 2018.

[27] Y. Peng et al., "Current status of machine prognostics in condition-based maintenance: a review," The International Journal of Advanced Manufacturing Technology, vol. 50, no. 1-4, pp. 297-313, 2010.

[28] Barajas et al., "Real-Time Diagnostics, Prognostics and Health Management for Large-Scale Manufacturing Maintenance Systems," Proceedings of the 2008 International Manufacturing Science and Engineering Conference, Evanston IL, Oct. 2008.

[29] X. Jin et al., "The Present Status and Future Growth of Maintenance in US Manufacturing: Results from a Pilot Survey," Manufacturing Review, vol. 3, pp. 1-10, 2016 in X. Jin, B. A. Weiss, D. Siegel, J. Lee, and J. Ni, Present Status and Future Growth of Advanced Maintenance Technology Strategy in US Manufacturing, vol. 7, no. 12, pp. $1-18,2016$.

[30] Feldman et al., "The Analysis of Return on Investment for PHM Applied to Electronic Systems," Proceedings of the International Conference on Pronostics and Health Management, Denver, CO. Oct. 2008. http://ieeexplore.iee.org/document/4711415/

[31] R. K. Mobley, “An introduction to predictive maintenance,” Elsevier. 2002.

[32] M. Kraus et al., "Forecasting remaining useful life: interpretable deep learning approach via variational Bayesian inferences," Decis. Support. Syst, vol. 125, 2019.

[33] Das K. et al., "A Survey on Machine Learning: Concept, Algorithms and Applications," International Journal of Innovative Research in Computer and Communication Engineering, vol. 5, no. 2, 2017.

[34] D. Delen et al., "A comparative analysis of machine learning systems for measuring the impact of knowledge management practices," Decision Support Systems, vol. 54, no. 2, pp. 1150-1160, 2012.

[35] A. S. S. Vasan et al., "Diagnostic and Prognostic Methods for Analog Electronics Circuits," IEEE transaction on Industrial Electronics, vol. 60, no. 11, Nov. 2013.

[36] B. Long et al., "Research on Features for Diagnostics of Filtered Analog Circuits Based on LS-SVM," 2011 IEEE AUTOTESTCON, Baltimore, 2011, pp. 360-366.

[37] A. S. S. Vasan et al., "Experimental Validation of LS-SVM Based Fault Identification in Analog Circuits Using Frequency Features," Engineering Asset Management, pp. 629-641, 2011.

[38] X. S. Zhang et al., "Fault Prognostic Technogy of Complex Electronic Equipment for PHM," 2013 International Conference on Quality, Reliability, Risk, Maintenance, and Safety Engineering, Chengdu, 2013, pp. 1790-1792. 
[39] L. Hong-da et al., "Intelligent Fault Diagnosis Method in Controlled Rectifiers Based on Support Vector Machines," 2010 Second WRI Global Congress on Intelligent Systems, Wuhan, 2010, pp. 235-238.

[40] J. Wang et al., "Analog circuits Faults Diagnosis Method Based on CPSO-SVM," 2011 International Conference on Quality, Reliability, Risk, Maintenance, and Safety Engineering, Xi'an, 2011, pp. 465-468.

[41] S. Chen et al., "A new analog circuit fault diagnosis approach based on GA-SVM," 2013 IEEE International Conference of IEEE Region 10 (TENCON 2013), Xi'an, 2013, pp. 1-4.

[42] Q. Ma et al., "A new decision tree approach of support vector machine for analog circuit fault diagnosis," Analog Integr Circ Sig Process, vol. 88, pp. 455-463, 2016.

[43] T. Jingyuan et al., "Analog Circuit Fault Diagnosis Using AdaBoost and SVM," 2008 International Conference on Communications, Circuits and Systems, Fujian, 2008, pp. 1184-1187.

[44] W. He et al., "A Naive-Bayes-Based Fault Diagnosis Approach for Analog Circuit by Using Image-Oriented Feature Extraction and Selection Technique," IEEE Access, vol. 8, pp. 5065-5079, 2020.

[45] M. Biglarbegian et al., "On condition monitoring of high frequency power GaN converters with adaptive prognostics,” 2018 IEEE Applied Power Electronics Conference and Exposition (APEC), San Antonio, TX, 2018, pp. $1272-1279$.

[46] P. Bilski, "Application of Random Forest to the Fault Detection in Analog Circuits," XI IMEKO World Congress "Measurement in Research and Industry", 2015.

[47] S. Heo, "Fault Detection and Classification Using ANN," IFAC PapersOnLine, vol. 51, no. 18, pp. 470-475, 2018.

[48] M. Biglarbegian et al., "Scalable Reliability Monitoring of GaN Power Converter Through Recurrent Neural Networks," 2018 IEEE Energy Conversion Congress and Exposition (ECCE), Portland, OR, 2018, pp. 7271-7277.

[49] Q. Sun et al., "Condition Monitoring and Prognosis of Power Converters Based on CSA-LSSVM," 2017 International Conference on Sensing, Diagnostics, Prognostics, and Control (SDPC), Shanghai, 2017, pp. 524529.

[50] W. Chen et al, "Data-Driven Approach for Fault Prognosis of SiC MOSFETs," in IEEE Transactions on Power Electronics, vol. 35, no. 4, pp. 4048-4062, Apr. 2020.

[51] B. Gou et al., "An Online Data-driven Method for Simultaneous Diagnosis of IGBT and Current Sensor Fault of 3Phase PWM Inverter in Induction Motor Drives," in IEEE Transactions on Power Electronics, vol. 35, no. 12, pp. 13281-13294, 2020.

[52] M. Pecht et al., "Physics-of-failure-based prognostics for electronic products," Transactions of the Institute of Measurement and Control, vol. 31, no. 3-4, pp. 309-322, 2009.

[53] F. O. Heimes, "Recurrent neural networks for remaining useful life estimation," in Proceedings of International Conference on Prognostics and Health Management, 2008, pp. 1-6.

[54] A. Heng et al., "Rotating machinery prognostics: State of the art, challenges and opportunities," Mechanical Systems and Signal Processing, vol. 23, no. 3, pp. 724-739, 2009.

[55] M. Seeger, "Gaussian processes for machine learning," International Journal of Neural Systems, vol. 14, no. 2, pp. 69-106, 2004.

[56] S. Mohanty et al., "Mixed Gaussian process and state-space approach for fatigue crack growth prediction," International Workshop on Structural Heath Monitoring, vol. 2, pp. 1108-1115, 2007.

[57] V. T. Tran et al., "Data-driven approach to machine condition prognosis using least square regression tree," Journal of Mechanical Science and Technology, vol. 23, pp. 1468-1475, 2009.

[58] K. Chakraborty et al., "Forecasting the behavior of multivariate time series using neural networks," Neural Networks, vol. 5, pp. 961-970, 1992.

[59] X. Yao, "Evolving artificial neural networks," Proceedings of the IEEE, vol. 87, no. 9, pp. 1423-1447, 1999.

[60] D. C. M. Dickson et al., "Gamma processes and finite time survival probabilities," Astin Bulletin, vol. 23, no. 2, pp. 259-272, 1993.

[61] L. R. Rabiner, "A tutorial on hidden Markov models and selected applications in speech recognition," Proceedings of the IEEE, vol. 77, no. 2, pp. 257-286, 1989.

[62] M. Jouin et al., "Degradations analysis and aging modeling for health assessment and prognostics of PEMFC," Reliability Engineering \& System Safety, vol. 148, pp. 78-95, 2016.

[63] J. B. Ali et al., "Accurate bearing remaining useful life prediction based on Weibull distribution and artificial neural network," Mechanical Systems and Signal Processing, vol. 5657, pp. 150-172, 2015.

[64] M. Jouin et al., "Particle filter-based prognostics: Review, discussion and perspectives," Mechanical Systems and Signal Processing, vol. 7273, pp. 2-31, 2016.

[65] M. E. Tipping, "Sparse Bayesian learning and the relevance vector machine," Journal of Machine Learning Research, vol. 1, pp. 211-244, 2001.

[66] H. Khorasgani et al., "Methodologies for system-level remaining useful life prediction," Reliability Engineering \& System Safety, vol. 154, pp. 8-18, 2016.

[67] Y. Maher et al., "Survey on deep learning applied to predictive maintenance," International Journal of Electrical \& Computer Engineering (IJECE), vol. 10, no. 6, pp. 5592-5598, Dec. 2020. 


\section{BIOGRAPHIES OF AUTHORS}

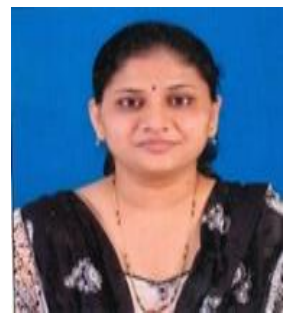

Soumya Rani Mestha received her Bachelor of Engineering degree in Electrical and Electronics Engineering (2009) and Master's in Power Electronics (2011) from VTU Belagaum. She is currently persuing doctoral program at NMAMIT Nitte. Presently serving as Assistant Professor in Electrical and Electronics Engineering Department, NMAMIT, Nitte, India. Her area of interest are predominantly in Machine Learning, Power Electronics, Relays and High Voltage.

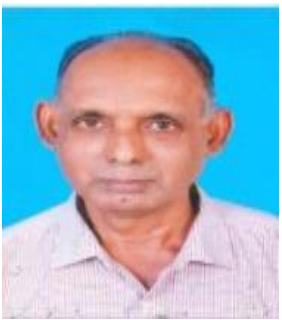

Dr. Pinto Pius A. J. received his B.E degree from Mysore University (1976) in Electrical Engineering, Master's from Mangalore university (1999) and $\mathrm{PhD}$ in Power Electronics from National Institute of technogy Karnataka, Surathkal (2008). He has twenty-six years of industry experience and 13 years experience in acamedics. Currently he is serving as a Professor in E\&E Engineering department, NMAMIT Nitte.His area of interest includes power electronics, electric vehicles, motors, and drives. 